\title{
Evaluation of Vimentin as a Potential Poor Prognostic Indicator and Salivary Biomarker for Oral Cancers and Pre-Cancers by Mass Spectrometry Based Proteomics
}

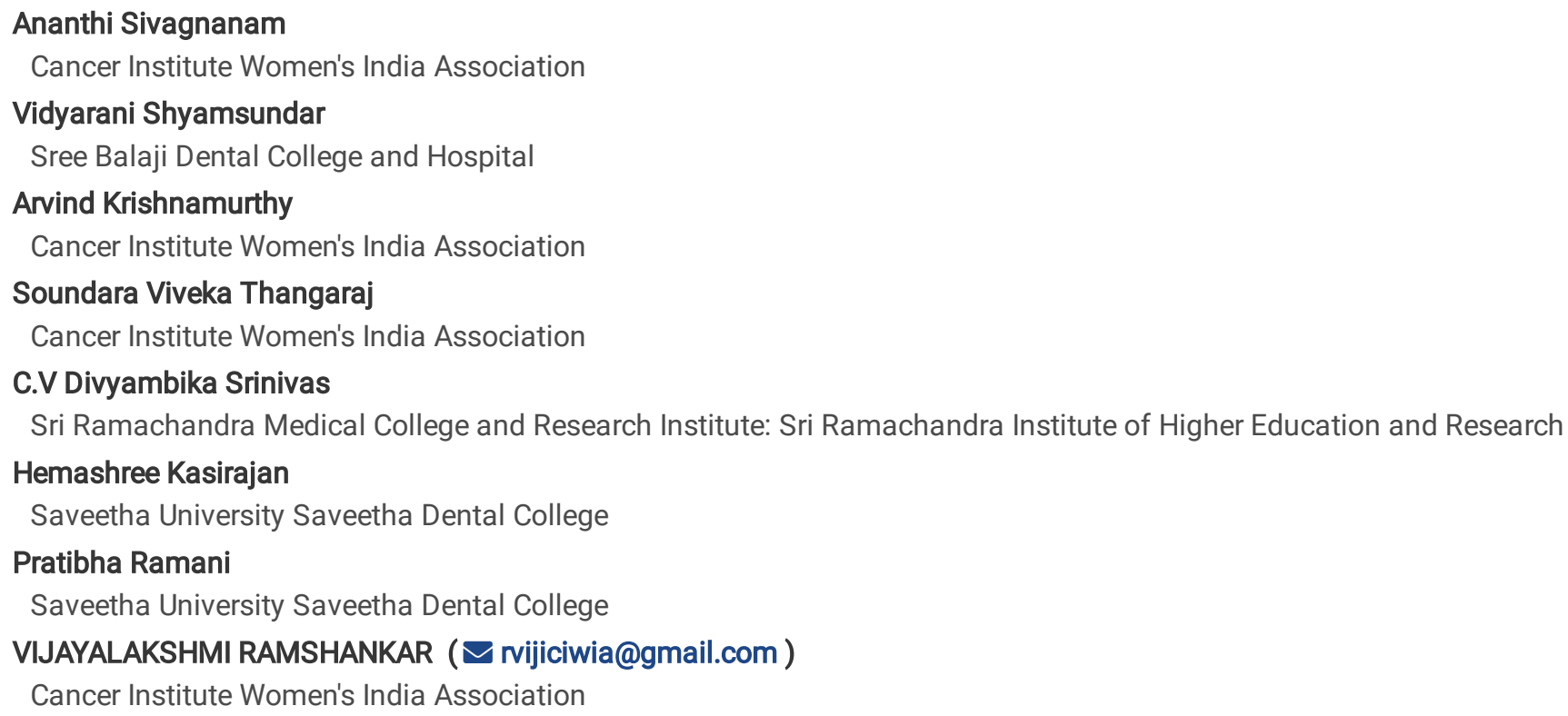

Research

Keywords: Tongue cancer, Vimentin, Saliva, Proteomics

Posted Date: June 30th, 2021

DOI: https://doi.org/10.21203/rs.3.rs-656555/v1

License: (c) (i) This work is licensed under a Creative Commons Attribution 4.0 International License. Read Full License 


\section{Abstract}

Background : Oral tongue squamous cell carcinoma (OTSCC) is an aggressive cancer with high morbidity and mortality rates, despite multimodality management. There are currently no clinically relevant molecular markers to help identify patients at a higher risk of recurrence and failure.

Methods: 2D-DIGE coupled with tandem mass spectrometry was performed on tissues obtained from early staged OTSCC along with its paired apparently adjacent normal tissue samples $(n=10)$. Top upregulated protein was validated using another independent set of tissue samples by Immunohistochemistry $(n=346)$, comprising of retrospective early stage OTSCC $(n=150)$ and prospective series of oral pre-cancers, normal and oral cancers $(n=195)$. For further validation of protein expression, saliva samples collected from Oral Cancer and pre-cancer samples were analysed by ELISA $(n=80)$.

Results: We found vimentin, the mesenchymal protein to be the most upregulated protein in tongue tumour tissues compared to adjacent apparent normal tissues. Vimentin was found to be significantly overexpressed in oral pre-cancers along with cancers compared to normal tissues.

Conclusion: Vimentin detection in saliva can be useful diagnostic test to detect oral precancers that may have malignant potential needing closer follow up. Salivary ELISA for vimentin can additionally be useful for disease monitoring in oral cancers.

\section{Background}

Oral Tongue Squamous cell carcinoma (OTSCC) represents a major portion of oral cavity cancers, especially in India. Studies show a sharp increase in the incidence of tongue cancers in India[1]. Our earlier studies on south Indian patient population have shown that early staged tongue cancers (T1 and T2) constitute nearly 45\% of all OTSCCs[2]. Studies have shown that OTSCC occurs at a younger age than cancers occurring in other subsites of oral cavity[3]. Despite being detected at an early stage about $40 \%$ of patients still die of the disease and need tailored treatment. Depth of invasion, tumour grade, perineural invasion are some of the factors indicating an aggressive phenotype but till date there are no relevant molecular markers indicating the high- risk tumours.

Proteomics helps to study the complete protein complements of the cell, which is a promising approach for the identification of novel protein biomarkers. These proteins can be used as key targets for therapeutic intervention and also as promising candidates for early detection of cancers $[4,5]$. We have some recent studies showing the preliminary application of proteomics for the identification of biomarkers for OSCC [6, 7]. Comparison of protein expression profiles between OSCC and normal cell lines or tissues has revealed replicable and significant changes in the expression levels of number of proteins, including some metabolic enzymes, modulators of signal transduction pathways, and oncoproteins[8]. In the current study, we have performed 2D DIGE based proteomic profiling coupled with mass spectrometry approach and have validated the expression of top upregulated protein Vimentin, eventually to explore the prognostic stratification of early staged OTSCC. We have additionally studied the vimentin expression in Oral precancers and cancers comparing with normal tissues. Salivary ELISA for vimentin has been attempted to evaluate the secretion of vimentin in samples from normal healthy volunteers comparing with saliva from patients presenting with oral leukoplakia, OSMF and Oral squamous cell carcinoma.

\section{Materials And Methods}

\section{Patients and tissue specimens}

All research involving human participants had been approved by the authors' Institutional Review Board (IRB) and all clinical investigations had been conducted according to the principles expressed in the Declaration of Helsinki. A written informed consent was obtained from all the participants and the content of the informed consent was approved by the respective Institutional Research Board namely, Cancer Institute WIA; Protocol 1 HNCOG (Cancer Institute, Women India Association; Protocol 1 Head and Neck Co- operative Oncology Group) SBDCECM105/13/58 (Sree Balaji Dental College and hospital Ethical Committee Meeting reference number 105/13/158) and the Department of Oral medicine and Radiology, Sree Ramachandra Dental College and hospital from June 2018 till January 2019. Institutional Ethics Committee approval (IEC No.CSP/17/AUG/60/239) and Ethics approval from Department of Oral and maxillofacial pathology, Saveetha Dental College and hospital from December 2017 to August 2019 (SRB/SDMDS11/170MP/01) was obtained before the commencement of the study.

\section{Patient tissue samples}


Histologically apparently normal adjacent tongue tissues along with paired early staged OTSCC tumour tissues $(n=10)$ were obtained from patients presenting with OTSCC and undergoing surgery. Formalin fixed paraffin embedded samples from buccal leukoplakia $(n=50)$, oral cancers $(n=71)$ were obtained from Sree Balaji Dental College and hospital and formalin fixed tissues from oral submucous fibrosis samples $(n=32)$ and normal buccal mucosa tissues $(n=42)$ were obtained during third molar extraction were collected from Sree Ramachandra Dental College and Hospital. This was an independent cohort $(n=195)$ for validation studies. Saliva samples $(n=80)$ were collected from oral cancer patients $(n=45)$, patients with oral potentially malignant lesions $(n=15)$ and normal $(n=20)$ obtained from Saveetha Dental College and Hospital and Sree Ramachandra Dental College and Hospital. Additionally, formalin fixed paraffin embedded sections from retrospective series of exclusively early staged tongue cancer patients [T1 and T2] ( $n=150)$ were obtained from Cancer Institute WIA who had been treated between 1995 to 200 for validation studies of the findings with the complete treatment follow up. All the FFPE sections $(n=345)$ used for the study were histologically examined by oral pathologist VS and PR.

\section{Patient Saliva samples}

ELISA was done for saliva samples $(n=80)$ collected from Oral cancer patients, patients presenting with oral potentially malignant lesions and absolute normal volunteers. The study participants were requested to refrain from drinking, eating, chewing tobacco or smoking 1 hour prior to the collection of saliva. After obtaining the informed consent of the patient, 0.5 to $1 \mathrm{ml}$ of whole unstimulated saliva was collected by passive expectoration and patients were asked to spit into a $50-\mathrm{mL}$ sterile tube containing $10 \mu \mathrm{L}$ of proteinase inhibitor (Proteinase inhibitor cocktail P2714 Sigma Aldrich). The saliva samples were transferred to 1.5-mL sterile microtubes and centrifuged for 3 minutes at 13,000 rpm. Supernatants, separated from the cellular phase, were immediately aliquoted and stored at $-80^{\circ} \mathrm{C}$ within 60 minutes after saliva collection.

\section{Proteomics - Proteins Labelling with CyDyes}

Pooled OTSCC tumour and pooled adjacent uninvolved tissues were used for the proteomic profiling. Lysine labelling protocol, (minimal labelling) used in this study is described before[9]. The processed tissue proteins were labelled individually with dyes Cy3 and Cy5 while the pooled tissue proteins prepared by mixing equal aliquot of protein from all samples in an experimental set up were labelled with Cy2. The final volume for all preparations was adjusted to a total of $340 \mathrm{uL}$ with rehydration buffer ( $7 \mathrm{M}$ urea, $2 \mathrm{M}$ thiourea, $1 \%$ IPG buffer, 50 mM DTT, 4\% CHAPS, and a trace amount of bromophenol blue). A reciprocal labelling experiment was also performed.

\section{Proteomics - 2D gel electrophoresis}

Two-dimensional gel electrophoresis of CyDye labeled proteins was done as described before[10, 11] with the following modifications. Eighteen cm IPG strips of pH 4-7 (GE Healthcare, Uppsala, Sweden) was employed in the first dimension. Labelled proteins were focused for a total of $80,000 \mathrm{Vhs}$ at a constant temperature $\left(20^{\circ} \mathrm{C}\right)$ under linear voltage ramp after an active IPG rehydration at $30 \mathrm{~V}$ in a IPGPhor III (GE Healthcare, Uppsala, Sweden) apparatus. Following IEF, each IPG strip was placed in the equilibration buffer containing $2 \%$ DTT first followed by incubation in another buffer in which the DTT was replaced by $2.5 \%$ iodoacetamide. The second dimension PAGE (12.5\%) was carried out in an EttanDaltSix systems (GE Healthcare, Uppsala, Sweden) at $1 \mathrm{~W} / \mathrm{gel}$ for $1 \mathrm{hr}$ and $13 \mathrm{~W} / \mathrm{gel}$ for $5 \mathrm{hr}$. All experimental procedures were performed in dim light or in the dark.

\section{Protein Visualisation and DeCyder Image analysis}

The protocols for the protein visualization and image analysis using DeCyder has been mentioned previously[12]. Briefly, after second dimension electrophoresis, the gels were scanned with Typhoon FLA 9500 Variable Mode Imager (GE Healthcare, Uppsala, Sweden). Cy2, Сy3 \& Cy5 images were captured using the settings recommended by the manufacturer. A DeCyder differential in-gel analysis (DIA) module was used for image analysis between samples within the same gel while a DeCyder biological variation analysis (BVA) module was performed for pairwise image analysis among multiple gels. Student's t-test and ANOVA were used to compare the average spot volume and differences of protein abundance for all detectable spots between the tumor and normal groups. Reciprocal dye labelling was performed to normalize bias in labelling.

\section{Protein Identification and Mass Spectrometry (MS)}

Pooled tongue tissue proteins $(250 \mu \mathrm{g})$ were separated on $18 \mathrm{~cm} \mathrm{IPG} \mathrm{strips} \mathrm{of} \mathrm{pH} \mathrm{4-7} \mathrm{in} \mathrm{the} \mathrm{first} \mathrm{dimension.} \mathrm{First} \mathrm{and} \mathrm{second} \mathrm{dimension}$ electrophoresis were done as given under 2D DIGE method. The second-dimension gels were stained with colloidal coomassie blue G250 and gel spots from this preparative gel were excised manually for in-gel trypsin digestion and LC-MS/MS was performed. Extracted peptides were dried under vacuum for $90 \mathrm{~min}$ and stored at $4{ }^{\circ} \mathrm{C}$. Zip tip purified peptides were analysed using nano-RPLC (Thermo 
Scientific, USA) coupled with an Orbitrap Elite Mass spectrometer (Thermo Scientific, USA). Peptides were ionized by positive mode electrospray with an ion spray voltage of $1.9 \mathrm{kV}$. The MS data were acquired in positive ion mode over mass range $\mathrm{m} / \mathrm{z} 350-4000 \mathrm{Da}$ using Xcalibur software (version 2.2.SP1.48) (Thermo Scientific USA). MS data were analysed using Proteome Discoverer software v.1.4 (Thermo Scientific) using Sequest algorithm with database downloaded from Uniprot as described earlier[12]. The combined list of official gene symbols corresponding to the identified proteins was used for input. We used STRING (www.string.db.org)[13] network construction.

\section{Immunohistochemistry (IHC)}

The IHC detection methods was as mentioned previously[14]. Briefly, IHC for vimentin was performed on $5 \mu \mathrm{m}$ sections of FFPE tissues. The sections were deparaffinized in xylene and rehydrated in absolute ethanol. Antigen retrieval was done with $0.05 \mathrm{M}$ citrate Buffer (pH 9) in pressure cooker for 20 minutes. Endogenous peroxidase activity was blocked by incubation in $0.03 \%$ hydrogen peroxide in distilled water for 10 minutes and then washed with phosphate buffered saline (PBS). Sections were counterstained with hematoxylin, dehydrated, and mounted in DPX. Positive controls and negative controls were included appropriately where primary anti-body was replaced with $2 \%$ BSA in negative control. Immunostaining of the sections was reviewed with the corresponding haematoxylin and eosin-stained sections.

\section{IHC Scoring}

Immunohistochemical scoring for the target was done as described earlier[15]. Briefly, the percentage grade of stained tumor cells was scored as 0 , negative; $1,<10 \% ; 2,11-50 \% ; 3,51-80 \%$; or $4,>80 \%$ positive cells and the intensity of stain was scored as 0 , negative; 1 , weak; 2 , moderate; or 3 , strong. The immunoreactive (IR) score was calculated as a product of the percentage grade and intensity score with the IR score ranged from 0 to 12 . The immunoreactivity was divided into three groups on the basis of the final score: negative immunoreactivity was defined as a total score of 0 , low immunoreactivity was defined as a total score of $1-4$, and high immunoreactivity was defined as a total score $>4$. The immunostaining of the tumor invasive front was evaluated using the same method as mentioned for tumor areas.

\section{ELISA in Saliva Samples}

The RayBio® Human Vimentin ELISA (Enzyme-Linked Immunosorbent Assay) kit is used to quantify the expression of vimentin in saliva samples $(n=80)$, of which saliva samples from patients with oral cancer $(n=45)$, patients with oral potential pre-malignant lesions $(n=20)$ and healthy volunteers $(n=15)$ were used. This is an in vitro enzyme-linked immunosorbent assay for the quantitative measurement of human Vimentin in saliva samples. This assay employs an antibody specific for human Vimentin coated on a 96-well plate. Standards and samples are pipetted into the wells and Vimentin present in a sample is bound to the wells by the immobilized antibody. The wells are washed and biotinylated anti-human Vimentin antibody is added. After washing away unbound biotinylated antibody, HRPconjugated streptavidin is pipetted to the wells. The wells are again washed, a TMB substrate solution is added to the wells and color develops in proportion to the amount of Vimentin bound. The Stop Solution changes the color from blue to yellow, and the intensity of the color is measured at $450 \mathrm{~nm}$. The standard graph was plotted with the vimentin standard protein provided in the kit. Using the standard graph the protein concentration were extrapolated for the unknown OD values obtained from saliva samples obtained from patients and healthy volunteers.

\section{Statistical analysis}

The relative levels of stained protein spots compared with the internal standard spots were analyzed by DeCyder Difference In-gel Analysis (DIA) and DeCyder Biological Variation Analysis (BVA) software modules (GE Healthcare). Student's $t$-test was used to calculate statistically significant differences between 2 groups in relative abundance of individual protein spots among the groups in 2D-DIGE. P<0.05 was considered statistically significant. Other statistical analysis was done using SPSS (IBM Corporation version 16).

\section{Results}

\section{Quantitative proteomics using 2D DIGE and Mass Spectrometry in OTSCC shows vimentin as the most upregulated differentially expressed protein in early staged tongue cancer}

Comparative proteomic analysis of pooled tongue tissue samples obtained from OTSCC patients compared to pooled adjacent apparent normal samples are shown in Fig. 1. More than 95 protein pairs were obtained in the image analysis platform, among which

Page 4/19 
45 were upregulated in tumour samples compared with adjacent normal protein samples. Out of the differentially expressed proteins, top 10 differentially expressed spots were taken for mass spectrometry. Table 1 describes the protein identification details for the differentially regulated proteins with the accession number matched in the database, mass spec probability score, percentage of sequence coverage match. Table 2 describes the average fold ratio with ANOVA value for differentially regulated proteins. The top 10 differentially regulated proteins have been listed in Table 2, in which eight proteins were significantly upregulated and two proteins were significantly downregulated in tumour samples. Quantitative 2D-DIGE proteomic approach coupled with tandem mass spectrometry identified, Vimentin as the topmost upregulated protein in OTSCC (Fig. 1a). 
Table 1

List of differentially regulated proteins identified using Mass spectrometry

\begin{tabular}{|c|c|c|c|c|c|c|c|c|c|c|c|}
\hline $\begin{array}{l}\text { Spot } \\
\text { ID }\end{array}$ & Accession & Description & Score & Coverage & $\begin{array}{l}\text { \# } \\
\text { Proteins }\end{array}$ & $\begin{array}{l}\text { \# } \\
\text { Unique } \\
\text { Peptides }\end{array}$ & $\begin{array}{l}\text { \# } \\
\text { Peptides }\end{array}$ & $\begin{array}{l}\text { \# } \\
\text { PSMs }\end{array}$ & $\begin{array}{l}\# \\
\text { AAs }\end{array}$ & $\begin{array}{l}\mathrm{MW} \\
\text { [kDa] }\end{array}$ & $\begin{array}{l}\text { calc. } \\
\text { pl }\end{array}$ \\
\hline 1 & BOYJC4 & $\begin{array}{l}\text { Vimentin OS = } \\
\text { Homo sapiens } \\
\text { GN = VIM PE = } 3 \\
\text { SV = 1 - } \\
\text { [BOYJC4_HUMAN] }\end{array}$ & 76.06 & 51.97 & 31 & 12 & 28 & 52 & 431 & 49.6 & 5.25 \\
\hline 2 & P60174 & $\begin{array}{l}\text { Triosephosphate } \\
\text { isomerase OS = } \\
\text { Homo sapiens } \\
\text { GN = TPI1 PE = } 1 \\
\text { SV = 3- } \\
\text { [TPIS_HUMAN] }\end{array}$ & 52.41 & 49.30 & 3 & 2 & 13 & 29 & 286 & 30.8 & 5.92 \\
\hline 3 & P30041 & $\begin{array}{l}\text { Peroxiredoxin-6 } \\
\text { OS = Homo } \\
\text { sapiens GN = } \\
\text { PRDX6 PE = } 1 \mathrm{SV} \\
=3- \\
\text { [PRDX6_HUMAN] }\end{array}$ & 49.05 & 51.79 & 3 & 9 & 13 & 31 & 224 & 25.0 & 6.38 \\
\hline 4 & P30084 & $\begin{array}{l}\text { Enoyl-CoA } \\
\text { hydratase, } \\
\text { mitochondrial OS } \\
=\text { Homo sapiens } \\
\text { GN = ECHS1 PE = } \\
1 \mathrm{SV}=4 \text { - } \\
\text { [ECHM_HUMAN] }\end{array}$ & 63.59 & 45.86 & 1 & 9 & 15 & 39 & 290 & 31.4 & 8.07 \\
\hline 5 & P52565 & $\begin{array}{l}\text { Rho GDP- } \\
\text { dissociation } \\
\text { inhibitor } 1 \text { OS = } \\
\text { Homo sapiens N } \\
=\text { ARHGDIA PE = } 1 \\
\text { SV = 3 - } \\
\text { [GDIR1_HUMAN] }\end{array}$ & 135.67 & 57.35 & 8 & 10 & 20 & 138 & 204 & 23.2 & 5.11 \\
\hline 6 & Q32Q12 & $\begin{array}{l}\text { Nucleoside } \\
\text { diphosphate } \\
\text { kinase OS = Homo } \\
\text { sapiens GN = } \\
\text { NME1-NME2 PE = } \\
2 \text { SV = 1 - } \\
\text { [Q32Q12_HUMAN] }\end{array}$ & 43.60 & 47.60 & 9 & 4 & 9 & 21 & 292 & 32.6 & 8.48 \\
\hline 7 & P02671 & $\begin{array}{l}\text { Fibrinogen alpha } \\
\text { chain OS = Homo } \\
\text { sapiens GN = FGA } \\
\text { PE = } 1 \text { SV = } 2 \text { - } \\
\text { [FIBA_HUMAN] }\end{array}$ & 42.42 & 32.68 & 4 & 5 & 22 & 40 & 866 & 94.9 & 6.01 \\
\hline 8 & Q5I6Y6 & $\begin{array}{l}\text { Lamin A/C } \\
\text { transcript variant } \\
1 \text { OS = Homo } \\
\text { sapiens GN = } \\
\text { LMNA PE = } 2 \text { SV } \\
=1- \\
\text { [Q5I6Y6_HUMAN] }\end{array}$ & 29.77 & 20.18 & 9 & 6 & 11 & 17 & 664 & 74.0 & 7.18 \\
\hline 9 & P02144 & $\begin{array}{l}\text { Myoglobin OS = } \\
\text { Homo sapiens } \\
\text { GN = MB PE = } 1 \\
\text { SV = 2- } \\
\text { [MYG_HUMAN] }\end{array}$ & 81.93 & 68.83 & 8 & 8 & 16 & 50 & 154 & 17.2 & 7.68 \\
\hline
\end{tabular}




\begin{tabular}{|c|c|c|c|c|c|c|c|c|c|c|c|}
\hline $\begin{array}{l}\text { Spot } \\
\text { ID }\end{array}$ & Accession & Description & Score & Coverage & $\begin{array}{l}\text { \# } \\
\text { Proteins }\end{array}$ & $\begin{array}{l}\text { \# } \\
\text { Unique } \\
\text { Peptides }\end{array}$ & $\begin{array}{l}\text { \# } \\
\text { Peptides }\end{array}$ & $\begin{array}{l}\# \\
\text { PSMs }\end{array}$ & $\begin{array}{l}\# \\
\text { AAs }\end{array}$ & $\begin{array}{l}\text { MW } \\
\text { [kDa] }\end{array}$ & $\begin{array}{l}\text { calc. } \\
\text { pl }\end{array}$ \\
\hline 10 & P24844 & $\begin{array}{l}\text { Myosin regulatory } \\
\text { light polypeptide } \\
9 \text { OS = Homo } \\
\text { sapiens GN = } \\
\text { MYL9 PE = } 1 \mathrm{SV}= \\
4- \\
\text { [MYL9_HUMAN] }\end{array}$ & 51.33 & 54.65 & 9 & 7 & 9 & 25 & 172 & 19.8 & 4.92 \\
\hline
\end{tabular}

Table 2

List of differentially expressed proteins with regulation status, fold ratio and ANOVA

\begin{tabular}{|lllll|}
\hline Spot ID & Gene ID & Regulation status in Tumor & Average fold ratio & ANOVA \\
\hline 1 & VIM & UP & 4.89 & 0.00064 \\
\hline 2 & TPI1 & Up & 3.75 & 0.00047 \\
\hline 3 & PRDX6 & Up & 3.6 & 0.0041 \\
\hline 4 & ECHS1 & Up & 3.31 & 0.0007 \\
\hline 5 & ARHGDIA & Up & 2.89 & 0.00096 \\
\hline 6 & NME2 & Up & 2.13 & 0.0025 \\
\hline 7 & FGA & Up & 1.98 & 0.0045 \\
\hline 8 & LMNA & UP & 1.59 & 0.046 \\
\hline 9 & MB & Down & -1.5 & 0.021 \\
\hline 10 & MYL9 & Down & -1.92 & 0.0032 \\
\hline
\end{tabular}

Figure $1 \mathrm{~b}$ shows the highly upregulated protein vimentin marked in a box region across both the gels. The 3D view and the graphical log value of vimentin protein spot expression in 2D DIGE gel was analyzed and represented in Fig. 1c along with the magnified 2D gel view. The average ratio of upregulation of vimentin was 4.89 folds higher compared to the normal counterpart. The one-way ANOVA p value was found to be 0.00064 (Fig. 1d). The log standardized abundance was significantly high compared to the normal tissue protein (Fig. 1e).

\section{Functional classification of the identified Vimentin protein and biological network analysis reveals its significance in tumorigenesis}

The STRING[13] cluster analysis revealed that Vimentin forms a strong protein interaction with other partners, comprising of three major networks; first cluster is with most of the Small Nuclear Ribonucleo Proteins (SNRP) proteins; second cluster with different members of tropomyosin and third cluster with many caspases (Fig. 2). All these protein networks are known to have a key role in different tumorigenesis pathways; thus, this interaction analysis describes the significance of the identified Vimentin protein's regulation in tumorigenesis process.

\section{Validation of Vimentin Expression to evaluate the role in early staged OTSCC}

To validate the expression of Vimentin and its role in OTSCC, we undertook a retrospective cohort of exclusively early staged (T1 and T2) OTSCC patients $(n=150)$ treated as per the decision of the multispeciality board between 1995 to 2007 . The clinicopathological features of early staged OTSCCs analysed based on vimentin protein expression is shown in Table 3. Median age of the cohort was 55 years and median OS was 74 months and DFS was 22 months. The pattern of vimentin expression was predominantly cytoplasmic. Positive immunoreactivity for Vimentin was identified in 58 (38.6\%) patients and Vimentin was negative in $92(61.31 \%)$ patients. 
Table 3

Clinicopathological features of early stage OTSCC (with follow-up after treatment) analysed based on

\begin{tabular}{|c|c|c|c|c|}
\hline \multirow[t]{2}{*}{ Clinical Parameters } & $\mathbf{N}$ & Vimentin Negative $(n=92)$ & Vimentin & $P$ value \\
\hline & \multicolumn{2}{|l|}{150} & \multicolumn{2}{|l|}{ Positive $(n=58)$} \\
\hline \multicolumn{5}{|l|}{ Age } \\
\hline$<55$ years & 82 & $45(54.9)$ & $37(45.1)$ & \\
\hline$>55$ years & 68 & $47(69.1)$ & $21(30.9)$ & \\
\hline \multicolumn{5}{|l|}{ Sex } \\
\hline Male & 102 & $65(63.7)$ & $37(36.3)$ & \\
\hline Female & 48 & $27(56.2)$ & $21(43.8)$ & \\
\hline \multicolumn{5}{|l|}{ Site } \\
\hline Lateral border & 132 & $77(58.3)$ & $55(41.7)$ & \\
\hline Tip & 2 & 0 & $2(100)$ & $P=0.012$ \\
\hline Dorsum & 5 & $5(100)$ & 0 & \\
\hline Ventral Aspect & 11 & $10(90.9)$ & $1(9.1)$ & \\
\hline \multicolumn{5}{|l|}{ Stage } \\
\hline Stage 1 & 56 & $42(75)$ & $14(25)$ & $P=0.008$ \\
\hline Stage 2 & 94 & $50(53.2)$ & $44(46.8)$ & \\
\hline \multicolumn{5}{|l|}{ Tumor Size } \\
\hline $0-2 \mathrm{~cm}$ & 58 & $43(74.1)$ & $15(25.9)$ & \\
\hline $2.1-3 \mathrm{~cm}$ & 89 & $46(51.7)$ & $43(48.3)$ & $P=0.009$ \\
\hline$>3 \mathrm{~cm}$ & 3 & $3(100)$ & 0 & \\
\hline \multicolumn{5}{|l|}{ Pattern } \\
\hline Exophytic & 42 & $22(52.4)$ & $20(47.6)$ & \\
\hline Infiltrating & 88 & $52(59.1)$ & $36(40.9)$ & $P=0.014$ \\
\hline Ulcerated & 20 & $18(90)$ & $2(10)$ & \\
\hline \multicolumn{5}{|l|}{ Grade } \\
\hline WDSCC & 116 & $73(62.9)$ & $43(37.1)$ & \\
\hline Mod to poorly & 27 & $14(51.8)$ & $13(48.1)$ & \\
\hline \multicolumn{5}{|l|}{ Tobacco Habits } \\
\hline Chewer & 44 & $21(47.7)$ & $23(52.3)$ & \\
\hline Smoker & 27 & $19(70.4)$ & $8(29.6)$ & \\
\hline Chewer + Smoker & 17 & $12(70.6)$ & $5(29.4)$ & \\
\hline Non User & 62 & $40(64.5)$ & $22(35.5)$ & \\
\hline Alcohol (Yes) & 21 & $13(61.9)$ & $8(38.1)$ & \\
\hline \multicolumn{5}{|l|}{ Upfront Management } \\
\hline Observation & 73 & $51(69.9)$ & $22(30.1)$ & \\
\hline RND & 33 & $17(51.5)$ & $16(48.5)$ & \\
\hline
\end{tabular}




\begin{tabular}{|c|c|c|c|c|}
\hline \multirow[t]{2}{*}{ Clinical Parameters } & $\mathbf{N}$ & Vimentin Negative ( $n=92)$ & Vimentin & $P$ value \\
\hline & \multicolumn{2}{|l|}{150} & \multicolumn{2}{|l|}{ Positive $(n=58)$} \\
\hline Rad to Neck & 24 & $24(54.5)$ & $20(45.5)$ & \\
\hline \multicolumn{5}{|l|}{ Failure Pattern } \\
\hline No Evidence of Disease & 65 & $46(70.8)$ & $19(29.2)$ & \\
\hline Local Recurrence & 27 & $14(51.9)$ & $13(48.1)$ & $P=0.028$ \\
\hline Nodal Recurrence & 18 & $14(77.8)$ & $4(22.2)$ & \\
\hline Locoregional Recurrence & 39 & $18(46.2)$ & $21(53.8)$ & \\
\hline Distant Metastasis & 1 & 0 & $1(100)$ & \\
\hline \multicolumn{5}{|l|}{ Treatment Outcome } \\
\hline No Evidence of Disease (NED) & 65 & $46(70.8)$ & $19(29.2)$ & $P=0.038$ \\
\hline Failure & 85 & $46(54.1)$ & $39(45.9)$ & \\
\hline \multicolumn{5}{|l|}{ Survival } \\
\hline Alive - NED & 84 & 49 (58.3) & $34(40.4)$ & \\
\hline Alive with Disease & 4 & $4(100)$ & - & \\
\hline Dead & 63 & 39 (61.9) & $24(38.1)$ & \\
\hline
\end{tabular}

Numbers in the brackets indicate percentages

Vimentin expression was significantly correlated to higher clinical stage and increasing tumour size in early staged OTSCC

Among the vimentin positive tumours, $46.8 \%$ (44/94) belonged to stage 2 compared to $25 \%$ (14/56) in stage 1 which was significant statistically $\left(p=0.008 ; \chi^{2}=7.038\right)$. Among the vimentin positive tumours, $48.3 \%(43 / 89)$ had a tumour size $>2 \mathrm{~cm}$ compared to $25.9 \%$ $(15 / 58)$ of vimentin positive immune-expression in tumours of size less than $2 \mathrm{~cm}$ which was significant statistically $\left(p=0.009 ; \chi^{2}=\right.$ $9.394)$. There was decreased vimentin positivity identified in tongue tumours that was ulcerated $10 \%(2 / 20)$ compared to the exophytic and infiltrating $\left(p=0.014 ; \chi^{2}=8.536\right)$.

Vimentin expression was significantly correlated with failure of treatment, pattern of recurrence and poor progression free survival in early staged OTSCC

The patients with showing strong and positive immunoexpression of vimentin had a higher failure rates [45.9\% (39/85) vs $29.2 \%$ $(19 / 65)$ ] which was statistically significant, $\left(p=0.038 ; \chi^{2}=4.306\right)$ and the data was represented in Table 3 . Positive immunoexpression of vimentin was significantly associated with locoregional recurrence [53.8\% (21/39) vs $29.2 \%(19 / 65)]$ patients showing no evidence of disease which was significant statistically $\left(p=0.028 ; \chi^{2}=10.892\right)$.

\section{Vimentin expression at Invasive front of the tumours indicated failure of treatment and locoregional recurrence in early staged OTSCC}

Vimentin at ITF was positive in $47.6 \%(50 / 105)$ of patients whose tumours showed an invasive tumour front. Among the patients who showed locoregional recurrence with ITF in the tumours, 68\% (17/25) showed a positive vimentin at ITF compared to $32 \%(8 / 25)$ patients whose tumours ITF had negative immune-expression as shown in Table 4. 
Table 4

Vimentin expression at Invasive tumour front (ITF) vs pattern of failure in early staged OTSCC with treatment follow up

\begin{tabular}{|lllll|}
\hline Vimentin Status & $\begin{array}{l}\text { No Evidence of Disease } \\
\text { (NED) }\end{array}$ & $\begin{array}{l}\text { Local } \\
\text { Recurrence }\end{array}$ & $\begin{array}{l}\text { Nodal } \\
\text { Recurrence }\end{array}$ & $\begin{array}{l}\text { Locoregional } \\
\text { recurrence }\end{array}$ \\
\hline $\begin{array}{l}\text { Negative expression at ITF }(n= \\
55)\end{array}$ & $28(50.9)$ & $9(16.4)$ & $10(18.2)$ & $8(32)$ \\
\hline $\begin{array}{l}\text { Positive expression at ITF }(n= \\
50)\end{array}$ & $20(40)$ & $10(20)$ & $3(16)$ & $17(68)$ \\
\hline
\end{tabular}

$P=0.002 ; \chi 2=14.792$ (numbers in brackets denote percentages)

Patients undergoing modified neck dissection for neck management had the best survival among the early staged OTSCC

Patients whose tumours had positive vimentin expression had an decreased DFS compared to the patients whose tumours had negative vimentin expression and this association was statistically significant (Log Rank $=4.068 ; p=0.044)$ (Fig. 3a). The patients in this cohort were subjected to upfront neck management, namely neck node observation $(n=73)$, modified radical neck dissection [MRND] $(n=33)$ and radiation to neck $(n=44)$. Kaplan Meier survival curves of DFS based on upfront neck management showed that patients who underwent MRND having a better survival $(p=0.006$; log rank $=10.094)$ compared to patients given radiation to neck. (Fig. $3 b)$

\section{Vimentin expression correlates with severity of dysplasia in oral pre-cancers and indicates malignant potential}

Based on the findings of the retrospective study, we undertook another cohort of patients $(n=196)$ with oral leukoplakia $(n=50)$, OSMF $(n=32)$ and invasive cancers involving buccal cavity (to ascertain if Vimentin can useful in oral cancer inclusive of both sites oral tongue and buccal cavity. This cohort had 82 oral precancers comprising of leukoplakia $(n=50)$ and OSMF $(n=32)$ along with normals $(n=42)$ and Cancers of buccal cavity $(n=72)$. Table 5 shows the demographic details of subjects and patients who presented with oral pre-cancers at different stages and oral cancers presenting to the dental clinic. The median age of this group was 45 years. 
Table 5

Vimentin Expression in Oral Pre-cancers and Oral Buccal cancers along with Normal

\begin{tabular}{|c|c|c|c|c|}
\hline Clinical Parameters & $\begin{array}{l}N \\
195\end{array}$ & Vimentin Negative $(n=144)$ & $\begin{array}{l}\text { Vimentin } \\
\text { Positive }(n=51)\end{array}$ & P value \\
\hline \multicolumn{5}{|l|}{ Age } \\
\hline$<45$ years & 93 & $81(87.1)$ & $12(12.9)$ & $P=0.000$ \\
\hline$>45$ years & 102 & $63(61.8)$ & $39(38.2)$ & $x 2=16.163$ \\
\hline \multicolumn{5}{|l|}{ Sex } \\
\hline Male & 139 & $107(77)$ & $32(23)$ & \\
\hline Female & 56 & $37(66.1)$ & $19(33.9)$ & \\
\hline \multicolumn{5}{|l|}{ Diagnosis } \\
\hline Normal & 42 & $42(100)$ & 0 & \\
\hline Mild Dysplasia & 24 & $22(91.7)$ & $2(8.3)$ & \\
\hline Moderate Dysplasia & 13 & $10(76.9)$ & $3(23.1)$ & \\
\hline Severe Dysplasia & 13 & $11(84.6)$ & $2(5.4)$ & $P=0.000$ \\
\hline OSMF & 32 & $31(96.8)$ & $1(3.2)$ & $x 2=77.037$ \\
\hline WDSCC & 40 & $17(42.5)$ & $23(57.5)$ & \\
\hline MDSCC & 29 & $9(31)$ & $20(69)$ & \\
\hline Verrucous & 3 & $3(100)$ & 0 & \\
\hline \multicolumn{5}{|l|}{ Habits } \\
\hline Pan & 96 & 70 (72.9) & $26(27.1)$ & \\
\hline Betel Quid & 35 & $21(60)$ & $14(40)$ & $P=0.045$ \\
\hline Sharp tooth & 64 & 53 (82.8) & $11(17.2)$ & $x 2=6.181$ \\
\hline
\end{tabular}

Numbers in the brackets indicate percentages

Vimentin expression was analysed by IHC in totally 195 samples, of which 144 samples (73.9\%) showed the vimentin negative expression and 51 samples (26\%) showed vimentin positive expression in IHC analysis. The median age of this cohort was 45 years and age had a significant association with the vimentin positive expression $\left(p=0.000 ; \chi^{2}=16.163\right)$. The immuno-expression pattern of vimentin is represented in Table 5 describing the positive expression of vimentin having a significant association $\left(p=0.000: \chi^{2}=\right.$ 68.524) with oral precancers and cancers compared to apparent normals. Interestingly, vimentin was significantly correlated to the dedifferentiated state of the oral precancers with oral cancers $\left(p=0.000 ; \chi^{2}=77.037\right)$. Vimentin is a significant biomarker for oral precancers that may have an aggressive potential to turn into malignancy. Figure 4 shows the IHC based patterns of vimentin expression in Oral cancers.

Vimentin secretion is significantly elevated in saliva samples obtained from Oral Cancer and Oral pre-cancer patients compared to healthy volunteers

Since tissue availability in oral cancers and pre-cancers involve invasive procedures as a biopsy, we wanted to evaluate if vimentin could be detected in saliva, as saliva can serve as a non-invasive medium for early detection and also for disease monitoring. Vimentin secretion in saliva could be detected as significantly high in Oral cancer and pre-cancer patients. The concentration obtained in salivary ELISA for Vimentin detection range from $2.3-6.4 \mathrm{ng} / \mathrm{ml}$ for healthy volunteer samples, for precancer samples, the concentration ranges from $4.5-16.8 \mathrm{ng} / \mathrm{ml}$ and for cancer samples, the concentration ranges from $4.8-127 \mathrm{ng} / \mathrm{ml}$. The fold increase between healthy volunteer sample and precancer samples were statistically significant. The differential expression was analysed using SPSS software and observed to be statistically significant and the data was represented in Fig. 5a. The diagnostic potential of the underlying 
pathological implication could be detected by ROC curve analysis showing AUC $=0.8$ which had a high statistical significance (Fig. $5 b$ \& $5 c)$.

\section{Discussion}

Vimentin is a well-known mesenchymal protein acting as a scaffold for signalling proteins that are important for cancer cell invasion[16] wound healing, tissue repair[17] tissue ageing and apoptosis[18, 19]. This study describes the role of vimentin that emerged as the most upregulated protein in OTSCC by quantitative proteomics. We have validated the expression of vimentin in early staged OTSCC inferring its role as a poor prognostic indicator. The role of vimentin was further evaluated in oral precancers and in saliva indicating that vimentin can be a very useful marker in oral cancer for determining prognosis and can be used for early detection of the disease in saliva and Oral precancer tissues. Vimentin can be good biomarker because none of the normal buccal mucosa tissues expressed vimentin as expression of vimentin is indicative of mesenchymal transition. The current study showed aberrant vimentin expression in oral premalignant lesions and oral cancers.

Previous study done as a meta-analysis of differentially expressed genes in OTSCCs has shown the comprehensive expression profiling of genes identifying the role of extracellular matrix with EMT based deregulation in OTSCC showing the role of tumour microenvironment in OTSCC with a number of extracellular matrix (ECM) components playing a crucial role in patient prognosis[14].

As the first step, we evaluated the global proteomic profiles in early staged oral tongue cancer samples by 2D DIGE followed by mass spectrometry analysis. 2D-DIGE technique enables direct comparison of protein profile between tumor and normal samples on the same single 2D gel, thus reducing technical variability which could affect the expression pattern of proteins. Recent studies have used the conventional 2D electrophoresis[7] and identified a panel of 12 proteins in tongue cancer, but absence of validations in normal tissues in the same gels can possibly lead to biased conclusions owing gel-to gel variations. To overcome this, we attempted 2D DIGE based proteomic discovery in the current study and have shown that proteins involved in cytoskeletal remodelling that are involved in the process of tumorigenesis. Proteomics approach can give rise to several markers, as shown in the current study but these biomarkers need to be chosen as per their clinical relevance based on validation studies Our studies has shown additional 9 top differentially regulated proteins that can be subsequently validated in oral cancer tissue and saliva samples. Along with vimentin, we also obtained laminin A/C transcript, myoglobin as significant markers by proteomics approach and they are well known stromal components playing important role in ECM modulation. Vimentin has been evaluated as a useful marker for aggressive pathology and poor prognosis in tongue cancers, its utility can be explored in patients to assess patients who are more likely to fail treatment, despite being early staged.

To validate this finding, as a second step, we evaluated the vimentin expression in retrospective series of exclusively early staged OTSCC. Early staged OTSCC need a biomarker to identify the patients who are more likely to fail despite being in T1 or T2 stage. The aggressive nature of OTSCC is reflected by the increased rates of local recurrence, occult node and distant metastasis. Though several histological features like extracapsular spread, perineural invasion, and presence of lymphovascular emboli are adverse factors, there is still an unanswered need of objective molecular markers that can be useful to identify patients needing further attention.

This study showed that upfront neck management was an important factor to predict event free survival. Patients who underwent modified neck dissection had the best overall survival among the early staged OTSCC showing the importance of neck dissection in OTSCC. This result was in agreement to the previous randomised controlled trial showing elective neck dissection showed higher rates of overall and disease-free survival in early staged OTSCC[20]. We did not find a significant correlation with overall survival and vimentin expression unlike the disease-free survival which is similar to previous reports[21]. Positive vimentin expression was found to be associated with increased stage, increased size of the tumour, increased treatment failures, increased locoregional recurrence and poorer disease-free survival. Earlier studies have identified vimentin over-expression to be a poor prognostic indicator in OTSCC by univariate analysis[21-24]. Our study confirms the earlier findings. It has been suggested that cancer cells present in the invasive tumour front (ITF) are more aggressive in terms of their metastatic potential[25]. Our study emphasises that expression of vimentin assessed at ITF can indicate the EMT switch which is known to be associated with increased motility and invasiveness. We found a significant association with locoregional recurrence and vimentin expression at ITF. Vimentin at ITF and tumour sites has been shown to be strongly correlated to aggressive phenotype contributing to poor prognosis[26]. Aberrant expression of vimentin has been incriminated in various epithelial cancers[27-32] including OSCC[33]. Vimentin has been shown as a predictive biomarker for tumor growth and metastasis, although its understanding is limited in OTSCC prognosis[34, 35].

As a third step, we wanted to evaluate the significance of vimentin in oral pre-malignant lesions that would comprise of leukoplakia, OSMF as well as buccal cancers. We wanted to evaluate if Vimentin can be a biomarker for oral cancers, comprising of both the major

Page $12 / 19$ 
sites buccal as well as tongue. We found a significant association of vimentin expression in oral precancers and cancers. Increased age was correlated to the vimentin expression mainly because of higher incidence of cancers in subjects with increasing age. Most of the potentially malignant disorders are asymptomatic and treatment can be of three types namely close observation, surgical excision/ablation and medical treatment. There is a lack of standardised diagnostic criteria in visual inspection of oral cavity to identify potentially malignant lesions that may eventually progress. Previous studies have shown Vimentin expression in lesions of leukoplakia and submucous fibrosis could be an early event in tobacco and areca nut associated tumorigenesis process.

As the fourth step, we have evaluated vimentin expression in saliva as a non-invasive means and have shown that vimentin can be a good marker for both early detection and disease monitoring in oral cancers. Our current study confirms this finding with a higher vimentin expression in saliva samples using ELISA method with a significant diagnostic potential for identifying patients with poor prognosis. This can be validated in higher number of samples of oral pre-cancers and cancers for early detection and disease monitoring. To our knowledge this is the first study evaluating vimentin in saliva from our country. Vimentin has been shown to be secreted by distinct population of vascular endothelial cells and activated macrophages and can accumulate in the blood previously[36, 37].

Vimentin secretion has been shown to be induced by pro-inflammatory cytokines TNF-a, and LPS suggesting that vimentin secretion is an inflammatory response[38]. We found that vimentin secretion was indeed very elevated in certain oral precancer samples that they could be an inflammatory response and more prone for malignant transformation in future.

A recent report reviewing all the promising biomarkers identified in tongue cancers have shown vimentin as one of the strongest biomarker with significant relevance as a marker with clinical utility[39] proving that it is an important marker of OTSCC which innately shows a higher propensity to metastasize confirming our reports. As per our findings Vimentin in pre-cancers can help identify patients most likely to progress to malignancy as is an useful early detection marker. In recent days, the non-invasive nature of saliva and its significant relationship with plasma levels made saliva an very attractive diagnostic tool[40].Up to our knowledge, this is the first report to describe the status of vimentin expression in saliva samples obtained from precancer, cancer patients with oral squamous cell carcinoma. Oral cancer is a very common cancer in Indian population and there were very few studies aimed to identify the biomarkers with validation study. We have identified the candidate proteins altered in our Indian population and validated them with both $\mathrm{IHC}$ and ELISA analysis.

\section{Conclusion}

In conclusion, 2D DIGE coupled with tandem mass spectrometry was found useful to identify differentially expressed proteins in OTSCC tissues. All the quantitative tissue proteomics-based markers identified in current study needs validation in OTSCC tissues as a prospective study with larger numbers of samples. The current study has been pursued for vimentin, a well characterised EMT marker. It was found clinically relevant to prognosticate early OTSCC patients most likely to fail treatment, requiring specific tailored treatment. Vimentin was also useful as an early detection biomarker of precancers in oral cavity. In addition, the vimentin protein expression has been validated in saliva samples obtained from precancer and cancer patients and found to be significantly upregulated when compared to normal samples, proving its role as a useful biomarker for early detection and disease monitoring.

\section{Declarations}

\section{Ethics approval and consent to participate}

For all the samples used in this study, the ethics approval had been obtained and the details were enclosed in the methodology section. The consent to participate in the study was obtained from all the patients.

\section{Consent for publication}

Not Applicable

\section{Availability of data and materials}

The datasets used and/or analysed during the current study are available from the corresponding author on reasonable request.

\section{Conflict of Interest Statement}

Page 13/19 
All authors disclose that there is no conflict of Interest.

Funding

This work was supported by grants from GOVERNMENT OF INDIA, MINISTRY OF SCIENCE \& TECHNOLOGY, DEPARTMENT OF BIOTECHNOLOGY - REFERENCE No. BT/PR18380/BIC/101/495/2016.

AUTHOR CONTRIBUTIONS

\begin{tabular}{|ll|}
\hline CONTRIBUTION & \\
\hline STUDY CONCEPT & AS, VR \\
\hline STUDY DESIGN & AS, VR \\
\hline DATA ACQUISITION & AS, TSV, VS, HK, CVD \\
\hline QUALITY CONTROL OF ALGORITHMS & AS, VS, PR, AK \\
\hline DATA ANALYSIS AND INTERPRETATION & AS, TSV, VR \\
\hline STATISTICAL ANALYSIS & AS, TSV, VR \\
\hline MANUSCRIPT PREPARATION & AS, AK, VR \\
\hline MANUSCRIPT EDITING & AS, AK, VR \\
\hline MANUSCRIPT REVIEW & AS, VS, PR, AK, TSV, HK, CVD,VR \\
\hline
\end{tabular}

Acknowledgements

This work was supported by grants from GOVERNMENT OF INDIA, MINISTRY OF SCIENCE \& TECHNOLOGY, DEPARTMENT OF BIOTECHNOLOGY - REFERENCE No. BT/PR18380/BIC/101/495/2016. We would acknowledge Dr T Balasankar, Clinbiocare Technology for his support towards proteomic analysis platforms.

\section{References}

1. Elango JK, Gangadharan P, Sumithra S, Kuriakose MA: Trends of head and neck cancers in urban and rural India. Asian Pacific journal of cancer prevention: APJCP 2006, 7(1):108-112.

2. Krishnamurthy A, Ramshankar V: Early stage oral tongue cancer among non-tobacco users-an increasing trend observed in a South Indian patient population presenting at a single centre. Asian Pacific journal of cancer prevention: APJCP 2013, 14(9):5061-5065.

3. Sopka DM, Li T, Lango MN, Mehra R, Liu JC-J, Burtness B, Flieder DB, Ridge JA, Galloway TJ: Dysplasia at the margin? Investigating the case for subsequent therapy in 'low-risk' squamous cell carcinoma of the oral tongue. Oral Oncology 2013, 49(11):1083-1087.

4. Herrmann PC, Liotta LA, Petricoin EF: Cancer proteomics: the state of the art. Disease Markers 2001, 17(2):49-57.

5. Johann DJ, McGuigan MD, Patel AR, Tomov S, Ross S, Conrads TP, Veenstra TD, Fishman DA, Whiteley GR, Petricoin EF et al: Clinical proteomics and biomarker discovery. Annals of the New York Academy of Sciences 2004, 1022:295-305.

6. Turhani D, Krapfenbauer K, Thurnher D, Langen H, Fountoulakis M: Identification of differentially expressed, tumor-associated proteins in oral squamous cell carcinoma by proteomic analysis. Electrophoresis 2006, 27(7):1417-1423.

7. He Q-Y, Chen J, Kung H-F, Yuen AP-W, Chiu J-F: Identification of tumor-associated proteins in oral tongue squamous cell carcinoma by proteomics. Proteomics 2004, 4(1):271-278.

8. Lee EJ, Kim SH, Kwark YE, Kim J: Heterogeneous nuclear ribonuclear protein C is increased in the celecoxib-induced growth inhibition of human oral squamous cell carcinoma. Experimental \& Molecular Medicine 2006, 38(3):203-209.

9. Ananthi S, Prajna NV, Lalitha P, Valarnila M, Dharmalingam K: Pathogen Induced Changes in the Protein Profile of Human Tears from Fusarium Keratitis Patients. PLOS ONE 2013, 8(1):e53018.

10. Ananthi S, Chitra T, Bini R, Prajna NV, Lalitha P, Dharmalingam K: Comparative analysis of the tear protein profile in mycotic keratitis patients. Molecular Vision 2008, 14:500-507 \%U https://www.ncbi.nlm.nih.gov/pmc/articles/PMC2268856/. 
11. Ananthi S, Santhosh RS, Nila MV, Prajna NV, Lalitha P, Dharmalingam K: Comparative proteomics of human male and female tears by two-dimensional electrophoresis. Experimental Eye Research 2011, 92(6):454-463.

12. Ananthi S, Lakshmi CNP, Atmika P, Anbarasu K, Mahalingam S: Global Quantitative Proteomics reveal Deregulation of Cytoskeletal and Apoptotic Signalling Proteins in Oral Tongue Squamous Cell Carcinoma. Scientific Reports 2018, 8(1):1-13 \%* 2018 The Author(s) \%U https://www.nature.com/articles/s41598-41018-19937-41593.

13. Szklarczyk D, Franceschini A, Wyder S, Forslund K, Heller D, Huerta-Cepas J, Simonovic M, Roth A, Santos A, Tsafou KP et al: STRING v10: protein-protein interaction networks, integrated over the tree of life. Nucleic Acids Research 2015, 43(Database issue):D447-452.

14. Thangaraj SV, Shyamsundar V, Krishnamurthy A, Ramani P, Ganesan K, Muthuswami M, Ramshankar V: Molecular Portrait of Oral Tongue Squamous Cell Carcinoma Shown by Integrative Meta-Analysis of Expression Profiles with Validations. PloS One 2016, 11(6):e0156582.

15. Liu L-K, Jiang X-Y, Zhou X-X, Wang D-M, Song X-L, Jiang H-B: Upregulation of vimentin and aberrant expression of E-cadherin/betacatenin complex in oral squamous cell carcinomas: correlation with the clinicopathological features and patient outcome. Modern Pathology: An Official Journal of the United States and Canadian Academy of Pathology, Inc 2010, 23(2):213-224.

16. Rodríguez MI, Peralta-Leal A, O'Valle F, Rodriguez-Vargas JM, Gonzalez-Flores A, Majuelos-Melguizo J, López L, Serrano S, de Herreros AG, Rodríguez-Manzaneque JC et al: PARP-1 regulates metastatic melanoma through modulation of vimentin-induced malignant transformation. PLoS genetics 2013, 9(6):e1003531.

17. Cheng F, Shen Y, Mohanasundaram P, Lindström M, Ivaska J, Ny T, Eriksson JE: Vimentin coordinates fibroblast proliferation and keratinocyte differentiation in wound healing via TGF- $\beta$-Slug signaling. Proceedings of the National Academy of Sciences of the United States of America 2016, 113(30):E4320-4327.

18. Nieminen M, Henttinen T, Merinen M, Marttila-Ichihara F, Eriksson JE, Jalkanen S: Vimentin function in lymphocyte adhesion and transcellular migration. Nature Cell Biology 2006, 8(2):156-162.

19. Danielsson F, Peterson MK, Caldeira Araújo H, Lautenschläger F, Gad AKB: Vimentin Diversity in Health and Disease. Cells 2018, 7(10).

20. Liu P-F, Kang B-H, Wu Y-M, Sun J-H, Yen L-M, Fu T-Y, Lin Y-C, Liou H-H, Lin Y-S, Sie H-C et al: Vimentin is a potential prognostic factor for tongue squamous cell carcinoma among five epithelial-mesenchymal transition-related proteins. PloS One 2017, 12(6):e0178581.

21. Han MW, Lee JC, Kim YM, Cha HJ, Roh J-L, Choi S-H, Nam SY, Cho K-J, Kim SW, Kim SY: Epithelial-Mesenchymal Transition: Clinical Implications for Nodal Metastasis and Prognosis of Tongue Cancer. Otolaryngology-Head and Neck Surgery 2015, 152(1):80-86 \%U https://doi.org/10.1177/0194599814556061.

22. Ding L, Zhang Z, Shang D, Cheng J, Yuan H, Wu Y, Song X, Jiang H: a-Smooth muscle actin-positive myofibroblasts, in association with epithelial-mesenchymal transition and lymphogenesis, is a critical prognostic parameter in patients with oral tongue squamous cell carcinoma. Journal of Oral Pathology \& Medicine: Official Publication of the International Association of Oral Pathologists and the American Academy of Oral Pathology 2014, 43(5):335-343.

23. Afrem MC, Mărgăritescu C, Crăiţoiu MM, Ciucă M, Şarlă CG, Cotoi OS: The immunohistochemical investigations of cadherin "switch" during epithelial-mesenchymal transition of tongue squamous cell carcinoma. Romanian Journal of Morphology and Embryology = Revue Roumaine De Morphologie Et Embryologie 2014, 55(3 Suppl):1049-1056.

24. D’Cruz AK, Vaish R, Kapre N, Dandekar M, Gupta S, Hawaldar R, Agarwal JP, Pantvaidya G, Chaukar D, Deshmukh A et al: Elective versus Therapeutic Neck Dissection in Node-Negative Oral Cancer. New England Journal of Medicine 2015, 373(6):521-529 \%U https://doi.org/510.1056/NEJMoa1506007.

25. Bànkfalvi A, Piffkò J: Prognostic and predictive factors in oral cancer: the role of the invasive tumour front. Journal of Oral Pathology \& Medicine: Official Publication of the International Association of Oral Pathologists and the American Academy of Oral Pathology 2000, 29(7):291-298.

26. Sawant SS, Vaidya Mm, Chaukar DA, Alam H, Dmello C, Gangadaran P, Kannan S, Kane S, Dange PP, Dey N et al: Clinical significance of aberrant vimentin expression in oral premalignant lesions and carcinomas. Oral Diseases 2014, 20(5):453-465.

27. Wulfkuhle JD, Liotta LA, Petricoin EF: Proteomic applications for the early detection of cancer. Nature Reviews Cancer 2003, 3(4):267-275.

28. Domagala W, Lasota J, Bartkowiak J, Weber K, Osborn M: Vimentin is preferentially expressed in human breast carcinomas with low estrogen receptor and high Ki-67 growth fraction. The American Journal of Pathology 1990, 136(1):219-227. 
29. Fuyuhiro Y, Yashiro M, Noda S, Kashiwagi S, Matsuoka J, Doi Y, Kato Y, Kubo N, Ohira M, Hirakawa K: Clinical Significance of Vimentin-positive Gastric Cancer Cells. Anticancer Research 2010, 30(12):5239-5243 \% U http://ar.iiarjournals.org/content/5230/5212/5239.

30. Li M, Zhang B, Sun B, Wang X, Ban X, Sun T, Liu Z, Zhao X: A novel function for vimentin: the potential biomarker for predicting melanoma hematogenous metastasis. Journal of experimental \& clinical cancer research: CR 2010, $29: 109$.

31. Al-Saad S, Al-Shibli K, Donnem T, Persson M, Bremnes RM, Busund L-T: The prognostic impact of NF-kappaB p105, vimentin, Ecadherin and Par6 expression in epithelial and stromal compartment in non-small-cell lung cancer. British Journal of Cancer 2008, 99(9):1476-1483.

32. Gilles C, Polette M, Piette J, Delvigne AC, Thompson EW, Foidart JM, Birembaut P: Vimentin expression in cervical carcinomas: association with invasive and migratory potential. The Journal of Pathology 1996, 180(2):175-180.

33. de Araujo VC, Pinto Júnior DS, de Sousa SO, Nunes FD, de Araujo NS: Vimentin in oral squamous cell carcinoma. European archives of oto-rhino-laryngology: official journal of the European Federation of Oto-Rhino-Laryngological Societies (EUFOS): affiliated with the German Society for Oto-Rhino-Laryngology - Head and Neck Surgery 1993, 250(2):105-109.

34. Mandal M, Myers JN, Lippman SM, Johnson FM, Williams MD, Rayala S, Ohshiro K, Rosenthal DI, Weber RS, Gallick GE et al: Epithelial to mesenchymal transition in head and neck squamous carcinoma. Cancer 2008, 112(9):2088-2100 \%* Copyright (C 2008 American Cancer Society \%U https://onlinelibrary.wiley.com/doi/abs/2010.1002/cncr.23410.

35. Wang C, Liu X, Huang H, Ma H, Cai W, Hou J, Huang L, Dai Y, Yu T, Zhou X: Deregulation of Snai2 is associated with metastasis and poor prognosis in tongue squamous cell carcinoma. International Journal of Cancer 2012, 130(10):2249-2258.

36. Xu B, deWaal RM, Mor-Vaknin N, Hibbard C, Markovitz DM, Kahn ML: The Endothelial Cell-Specific Antibody PAL-E Identifies a Secreted Form of Vimentin in the Blood Vasculature. Molecular and Cellular Biology 2004, 24(20):9198-9206 \%U https://www.ncbi.nlm.nih.gov/pmc/articles/PMC517872/.

37. Mor-Vaknin N, Punturieri A, Sitwala K, Markovitz DM: Vimentin is secreted by activated macrophages. Nature Cell Biology 2003, 5(1):59-63 \%* 2002 Nature Publishing Group \%U https://www.nature.com/articles/ncb2898.

38. Poulsom H, Charles PJ: Antibodies to citrullinated vimentin are a specific and sensitive marker for the diagnosis of rheumatoid arthritis. Clinical Reviews in Allergy \& Immunology 2008, 34(1):4-10.

39. Hussein AA, Forouzanfar T, Bloemena E, de Visscher J, Brakenhoff RH, Leemans CR, Helder MN: A review of the most promising biomarkers for early diagnosis and prognosis prediction of tongue squamous cell carcinoma. British Journal of Cancer 2018, 119(6):724-736.

40. Schipper RG, Silletti E, Vingerhoeds MH: Saliva as research material: Biochemical, physicochemical and practical aspects. Archives of Oral Biology 2007, 52(12):1114-1135 \%U https://linkinghub.elsevier.com/retrieve/pii/S0003996907001653.

\section{Figures}



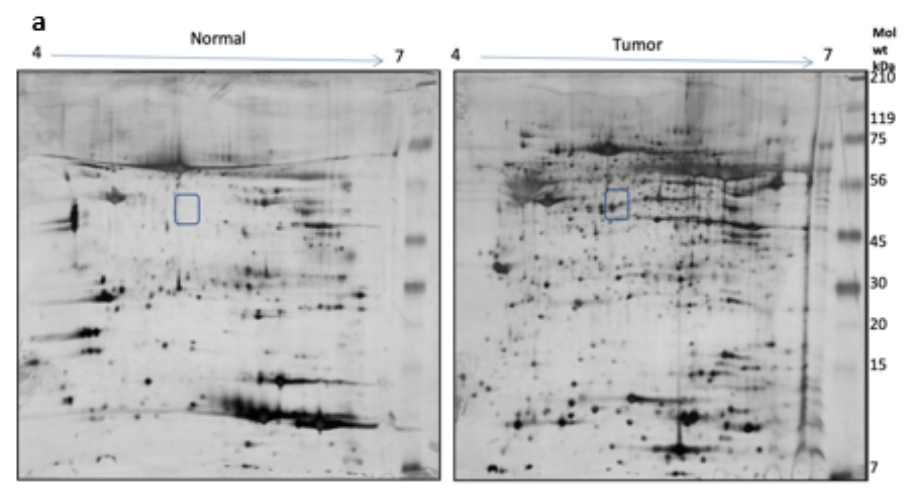

b
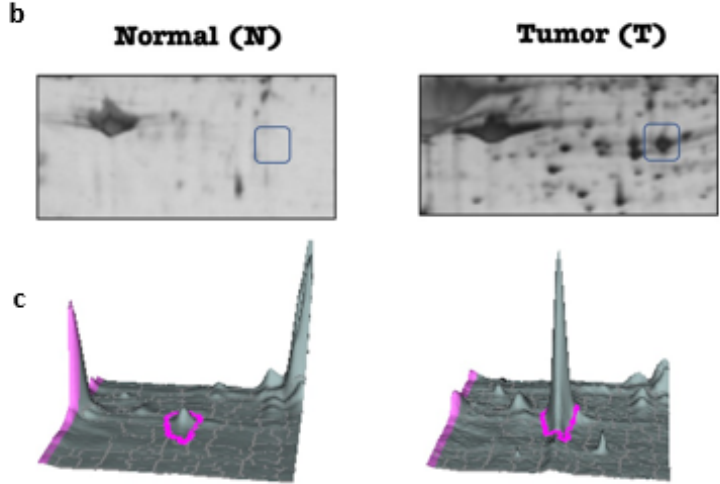

e

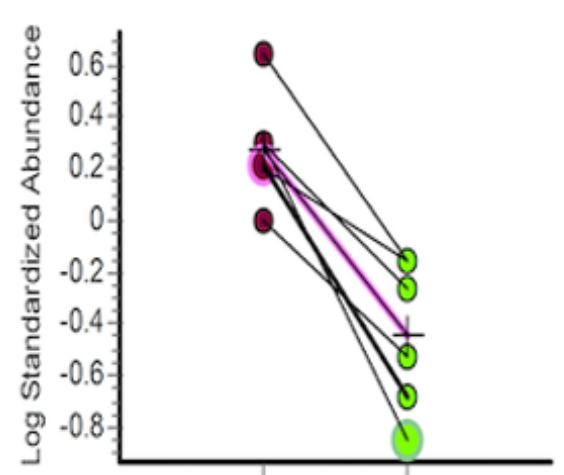

\section{Figure 1}

Representative 2DE gels of Normal and Tumor sample, 3D view, graphical representation and fold ratio analysis for differentially regulated proteins

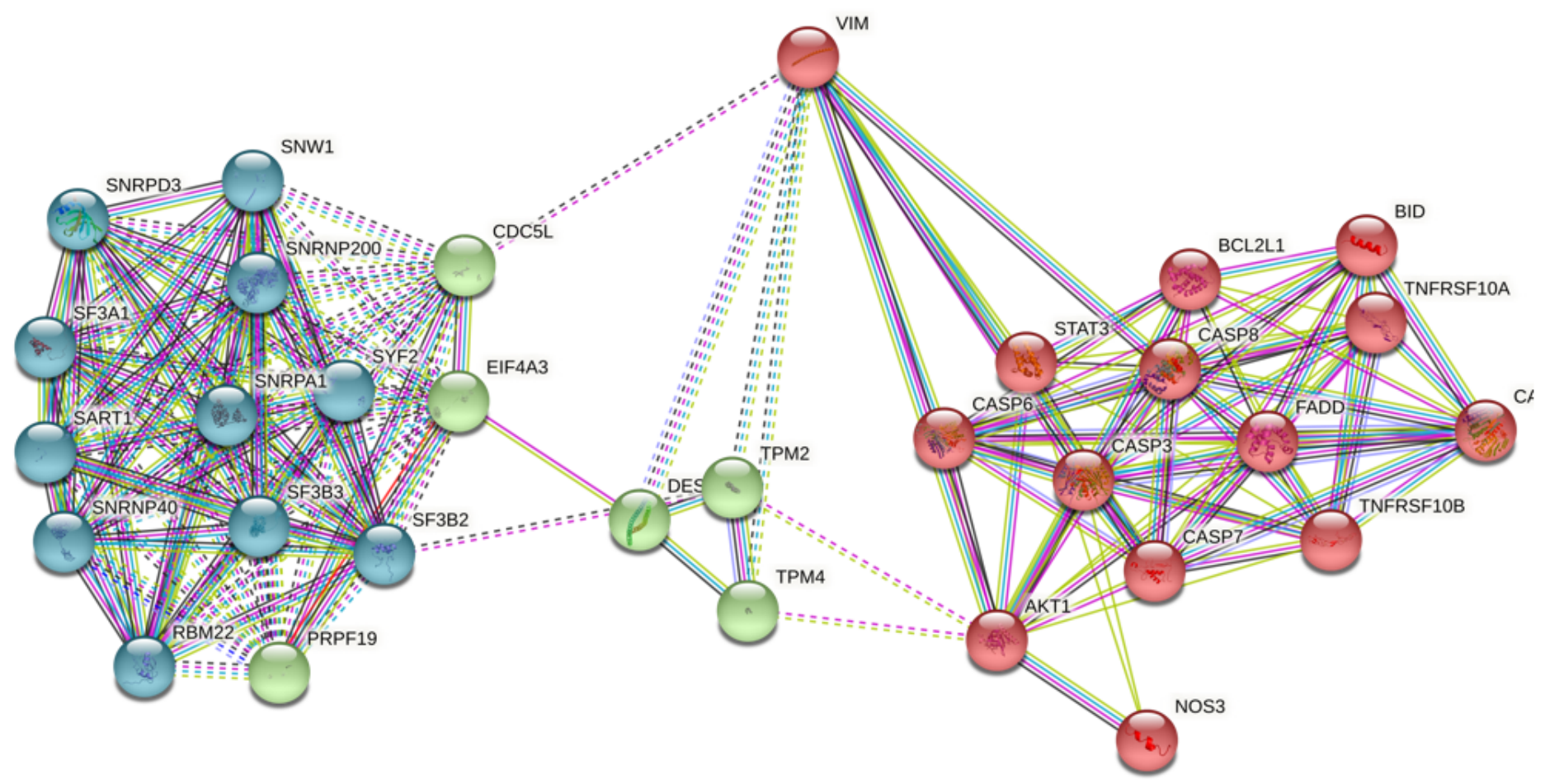

Figure 2

Cluster Analysis for the differentially regulated protein Vimentin using STRING database 

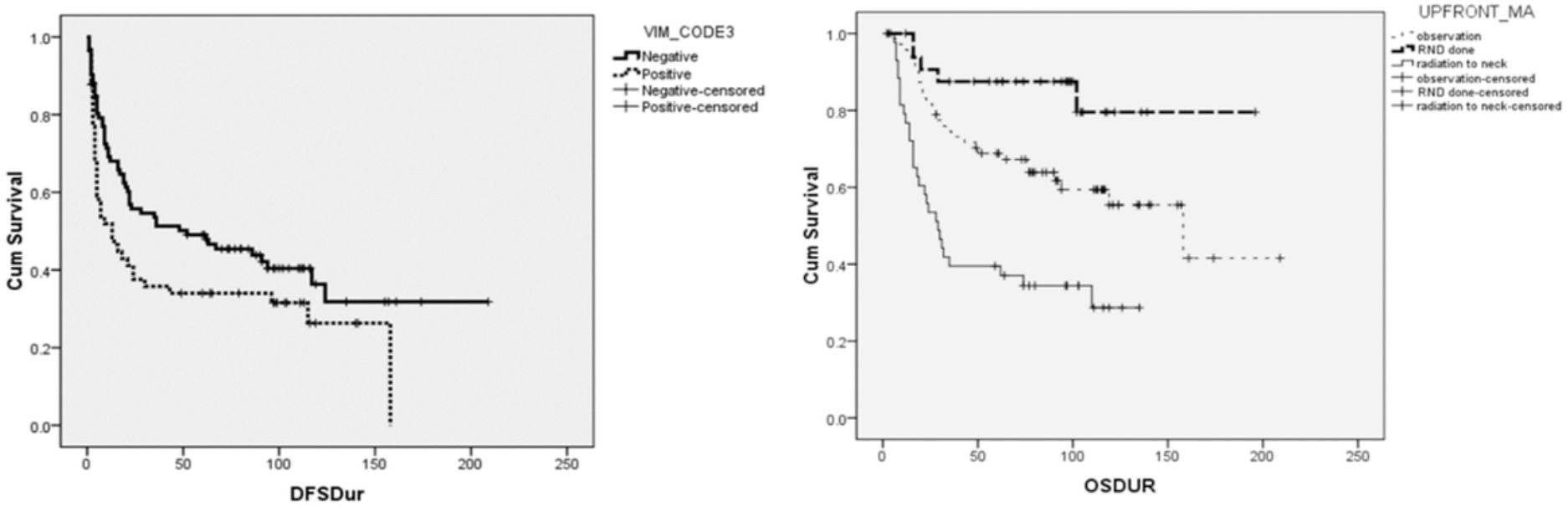

\section{Figure 3}

a : Kaplan Meier curves showing survival fractions in Patients with vimentin expression pattern b : Kaplan Meier curves showing survival fractions in Patients undergoing the different types of upfront neck management
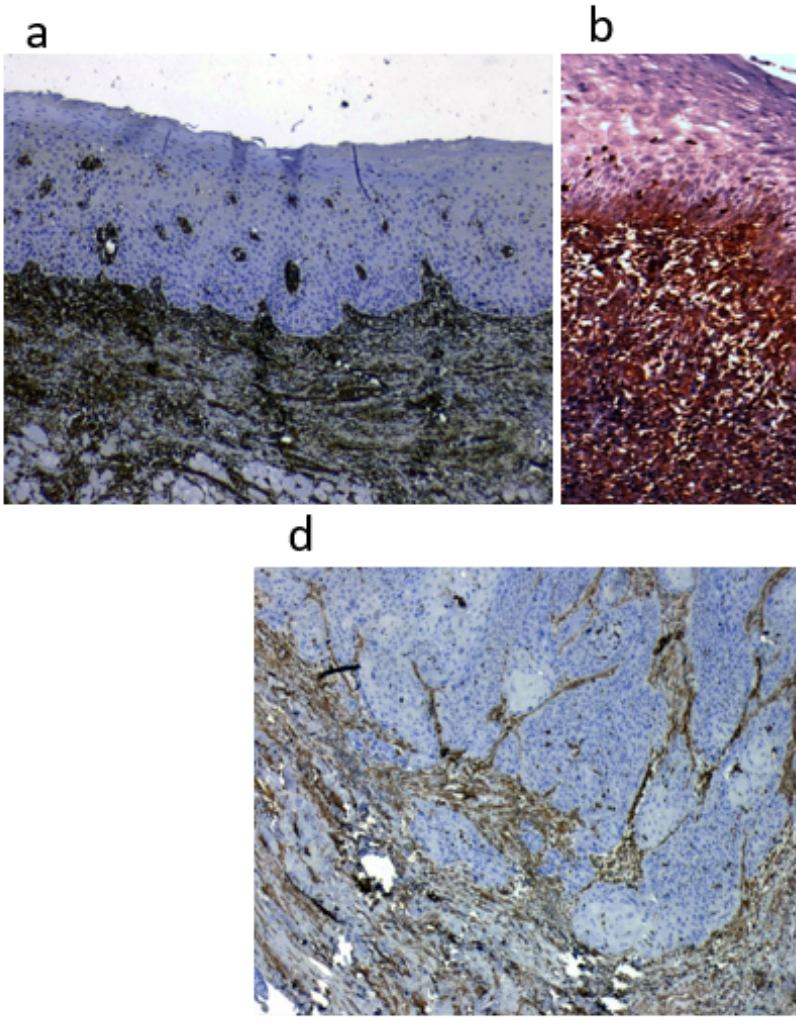

b

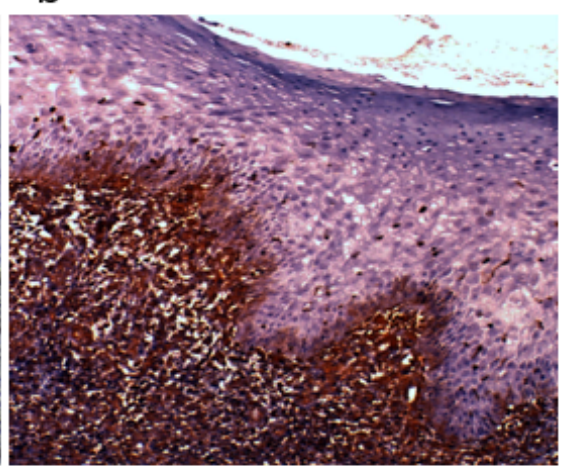

e
C

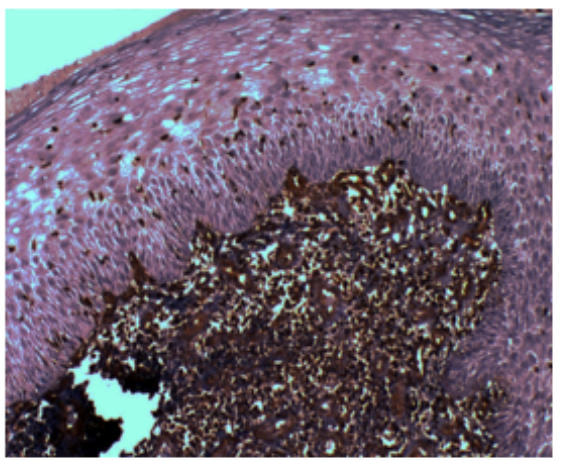

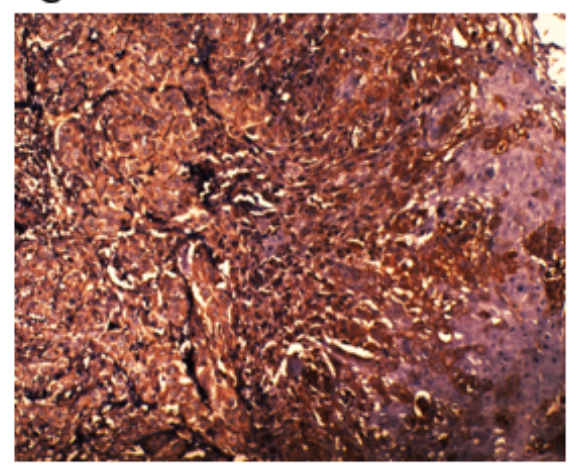

Figure 4

IHC analysis for Vimentin protein expression 
a

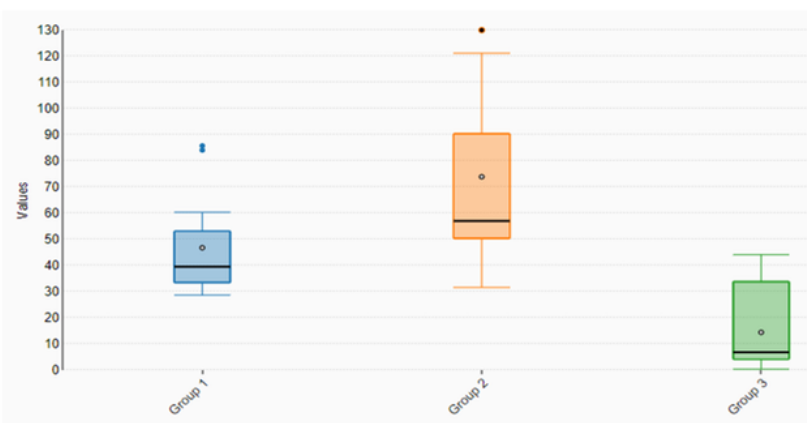

\begin{tabular}{|l|l|l|l|l|l|l|l|l|}
\hline \multicolumn{10}{|c|}{ DATA SUMMARY } \\
\hline \multicolumn{1}{|c|}{ Groups } & \multicolumn{1}{|c|}{ N } & \multicolumn{1}{c|}{ Min } & \multicolumn{1}{|c|}{ Q1 } & \multicolumn{1}{c|}{ Median } & \multicolumn{1}{c|}{ Q3 } & \multicolumn{1}{c|}{ Max } & \multicolumn{1}{c|}{ Mean } & SD \\
\hline Group 1 - OSMF & 15 & 29 & 33.47 & 39.51 & 53.055 & 85.76 & 46.76 & 18.08 \\
\hline Group 2 - Cancer & 45 & 32 & 50.35 & 57.01 & 90.35 & 289.93 & 73.93 & 43.91 \\
\hline Group 3 - Normal & 21 & 0 & 3.26 & 6.18 & 33.26 & 44.1 & 13.72 & 15.43 \\
\hline
\end{tabular}

b ROC Curve

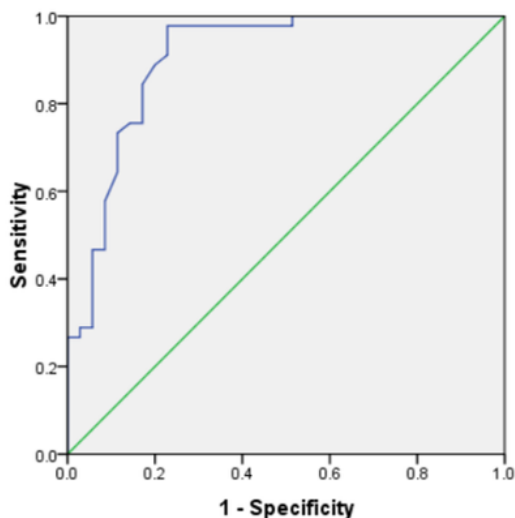

c

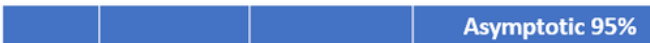

Area

Std.Error

Asymptotic

Confidence Interval

Significance

Lower Upper

Bound Bound

0.905

0.036

0.000

0.834

0.976

\section{Figure 5}

a: Scatter plot representation for Vimentin ELISA with data summary values b \& 5c: ROC curve, AUC analysis for Vimentin ELISA 